\title{
Novel oral anticoagulants in cataract surgery-moving towards a national consensus regarding perioperative continuation
}

\author{
Rupa Patel ${ }^{1} \cdot$ Tim De Klerk ${ }^{1}$
}

Received: 30 May 2019 / Accepted: 18 June 2019 / Published online: 8 July 2019

(c) The Royal College of Ophthalmologists 2019

Novel oral anticoagulants (NOACs), are increasingly used for prevention of VTE and stroke. Their preferential use over warfarin is based upon the convenience of fixed dosing, reduced risk of bleeding and the absence of the need to monitor blood levels.

National, European and international guidance regarding the cessation of NOACs prior to surgery with low bleeding risk varies. This undoubtedly is a consequence of the lack of direct large-scale data regarding this category of intervention, which includes cataract surgery.

Withholding NOACs prior to cataract surgery is safe, with a $1 \%$ risk of life-threatening thromboembolic events reported within 30 days post-op [1]. Soon after the emergence of NOACs, based on the evidence available at the time, our hospital implemented a policy of withholding one dose due immediately before planned cataract surgery. The dose was then taken $6 \mathrm{~h}$ after the procedure [2]. We reviewed the case notes of 252 patients that went through surgery with this policy in place and not one experienced a thromboembolic event.

Bleeding risks of warfarin in cataract surgery have been extensively studied and RCOphth guidelines currently advise that warfarin can continue if the INR is within the required range. NOACs confer a lower bleeding risk than warfarin [3]. We also know from a systematic review and meta-analysis that patients on NOACs have a $22 \%$ relative risk reduction of spontaneous intraocular bleeding compared with warfarin [4]. A further large-scale study also substantiates this, with a decreased spontaneous intraocular bleeding risk if continuing NOACs [5].

To our knowledge, only one small-scale study directly compares withholding and continuing NOACs during

Rupa Patel

rupapatel1@nhs.net

1 Manchester Royal Eye Hospital, Oxford Road, Manchester M13 9WL, UK cataract surgery. No increase in bleeding complications with NOAC continuation was found [6].

The above collated evidence supports the safety of continuing NOACs during cataract surgery. Evidence to the contrary is lacking. We have now updated our hospital policy to allow patients to continue NOACs during cataract surgery. We acknowledge that there may be instances where surgeons may request patients to stop the medication when perceived bleeding risk is extraordinarily high. In such cases, our data suggest that thromboembolic events would still be a rare occurrence.

\section{Compliance with ethical standards}

Conflict of interest The authors declare that they have no conflict of interest.

Publisher's note: Springer Nature remains neutral with regard to jurisdictional claims in published maps and institutional affiliations.

\section{References}

1. Beyer-Westendorf J, Gelbricht V, Förster K, Ebertz F, Köhler C, Werth S, et al. Peri-interventional management of novel oral anticoagulants in daily care: results from the prospective Dresden NOAC registry. Eur Heart J. 2014;35:1888-96.

2. Heidbuchel $\mathrm{H}$, Verhamme $\mathrm{P}$, Alings $M$, Antz M, Hacke W, Oldgren J, et al. EHRA Practical Guide on the use of new oral anticoagulants in patients with non-valvular atrial fibrillation: executive summary. Eur Heart J. 2013;34:2094-106.

3. Eikelboom J, Merli G. Bleeding with direct oral anticoagulants vs warfarin: clinical experience. Am J Med. 2016;129:S33-S40.

4. Sun M, Wood M, Chan W, Selva D, Sanders P, Casson R, et al. Risk of intraocular bleeding with novel oral anticoagulants compared with warfarin. JAMA Ophthalmol. 2017;135:864.

5. Uyhazi K, Miano T, Pan W, VanderBeek B. Association of novel oral antithrombotics with the risk of intraocular bleeding. JAMA Ophthalmol. 2018;136:122.

6. Cheung J, Liu S, Li K. Phacoemulsification cataract surgery in patients receiving novel oral anticoagulant medications. Int Ophthalmol. 2018;39:623-30. 